\title{
AMBIVALENT IMPACT OF CUSTOMER SATISFACTION ON FIRM VALUE IN EMERGING MARKETS: THE CASE OF KOREA
}

\author{
Hyunseok KIM${ }^{1}$, Jaisang $\mathrm{KIM}^{2}$, Kyeong-Seop $\mathrm{CHOI}^{3}$ \\ ${ }^{1,3}$ SKK Business School, Sungkyunkwan University, Seoul 110-745, Republic of Korea \\ ${ }^{2}$ Shidler College of Business, University of Hawaii at Manoa, HI 96822, USA \\ E-mails:1khs319@naver.com; ${ }^{2}$ jaisang@hawaii.edu; \\ ${ }^{3}$ kyeongchoi78@hanmail.net (corresponding author)
}

Received 16 March 2016; accepted 11 December 2016

\begin{abstract}
Many researchers report that American Customer Satisfaction Index relates significantly and positively to firm value. The purpose of this paper is to examine whether such relation holds in the emerging markets such as Korea. Our preliminary OLS analysis reports that Korean customer satisfaction is irrelevant to firm value. Quantile regressions, applied for further analysis, report that customer satisfaction can be detrimental to firm value if the firm is enjoying the higher kind of value. These results undermine efforts, on the theoretical level, to establish Customer Satisfaction Index as a consolidated firm-value indicator; furthermore, managerial efforts to boost up firm value by managing customer satisfaction lose ground in the emerging markets.

This study also corroborates Reinartz and Kumar's (2002) marketing insight that to satisfy customers, make them loyal, is trivial for profitability and firm value in Korea perspective.

The practical implication of our finding is that the relation between customer satisfaction and firm value becomes more ambiguous, especially when it is considered in the emerging market contexts. It also provides management with a fresh new insight that they should take prudence when they increase expenses on customer satisfaction since it turned out to be not a "panacea".
\end{abstract}

Keywords: National Customer Satisfaction Index (NCSI), firm value, R\&D, advertisement, chaebol, quantile regression.

JEL Classification: G32, M31.

\section{Introduction}

The limitations of financial indicators in predicting and evaluating firm value and performance have been addressed by many branches of business research. Other than financial indicators, innovation is pinned down as a driver of firm value and performance (Cooper 1984; Pauwels et al. 2004); sales promotion is also counted as such a driver (Pauwels et al. 2004); human capital (Huselid 1995; Vomberg et al. 2015); customer satisfaction (Anderson et al. 1994; Ittner, Larcker 1998; Anderson et al. 
2004; Luo et al. 2010; Sorescu A., Sorescu S. M. 2016; Fornell et al. 2016); corporate social responsibility (Cochran, Wood 1984; Servaes, Tamayo 2013). In this paper, we investigate whether and how customer satisfaction relates to firm value. Contrary to our common intuition, prior literature on the relation between customer satisfaction and firm value reports ambivalent results, especially when it is based on data from emerging markets such as Korea.

Marketers' and our intuition is that customer satisfaction would relate to firm performance and value positively (e.g. The Economist 2001, 2012). Anderson et al. (1994) report that customer satisfaction has variant effects on profitability whether it is in product or service industry. Fornell et al. (2006) predict on customer satisfaction and firm value as follows. Prior literature reports that customer satisfaction increases customer loyalty, usage levels, and future revenues; customer satisfaction reduces the future costs of transaction, price elasticity, and customer defection; furthermore, it reduces the costs incurred by complaints, warranties, and defective goods. Therefore, $a$ priori, "it seems logical to expect that these effects will eventually affect [...] company valuation" (Fornell et al. 2006: 4). Similarly, Anderson et al. (2004) empirically support their positive relation while testing the US data ${ }^{1}$.

The relation between customer satisfaction and firm value becomes more ambiguous, when it is considered in the emerging market contexts. Emerging market countries differ from developed market countries in their levels of GDP per capita, levels of financial, product market development, strengths of formal rights and their enforcement, and corporate ownership structures characterized by large group-affiliation (Claessens, Yurtoglu 2013). Moreover, their financial markets, highly susceptible to local information, are known to reveal less integration with developed markets (Harvey 1995; Blitz et al. 2013). Therefore, we can claim that to study our question in the emerging markets is meaningful and contributive. Our target country is Korea, which, nevertheless, does not lag far behind most of developed countries. Ahn and Kim (2000) report that, for Korean banks, customer satisfaction (i.e. NCSI) rarely significantly relates to profitability except for some extraordinary cases. Park and Kim (2003) report that such effects vary depending on industry. To the best of our knowledge, prior researches involving firm value, not performance, are very rare.

One possible reason why prior studies do not report consistent results would be that customers' (re)purchases do not relate to financial performances consistently depending on their levels of satisfaction. In general, higher customer satisfaction brings about higher customer loyalty, and furthermore, customers' persistent willingness to buy, regardless of external shocks such as price fluctuation. This drives firms' profit-making and enhances operating performance. Nevertheless, as the level of customer satisfaction exceeds a certain point, customers' expected quality on products exceeds the level that

\footnotetext{
${ }^{1}$ To make our definition more precise, we make clear that the variable "customer satisfaction" is simply its score (level), not the rate of its increase. As far as our knowledge goes, prior researches use its level, not its rate of increase in a single case. Here untabulated, our statistical results showed no qualitative difference, when we used its rate of increase for a robustness check.
} 
firms can afford and, customer satisfaction turns out to affect financial performance negatively (à la Ittner, Larcker 1998).

From our brief overview of prior literature, we find that prior studies examine the relation between customer satisfaction and firm performance (or value) through simple or multiple OLS regressions. However, OLS regressions modeling linear relationship between independent variables and the conditional mean of the dependent variable Tobin's Q (proxy for firm value) can distort our estimation results, because the distribution of Tobin's $Q$ is skewed. In order to address this issue, we consider quantile regressions more appropriate that model the relationship between independent variables and the conditional quantiles of the dependent variable Tobin's Q (Koenker, Bassett 1978). Therefore, in this paper, we adopt quantile regression (QR) technique and undertake a statistically detailed analysis of how customer satisfaction affects firm value for each quantile range of Tobin's Q. As far as our knowledge goes, we do not find any prior research of this kind.

The Korean corporate governance provides the unique and intriguing distinction between chaebols and non-chaebols. Chaebol refers to large business groups in Korea, holding plural product categories in a market, further diversified throughout multiple markets and industries. A large shareholder or a family owns a chaebol group and exerts influence on financial and managerial decisions for the entire group of firms (Shin, Park 1999). Chaebol groups suffer less from financial constraints, because they have internal capital markets networking their subordinate firms (Shin, Park 1999; Chang, Hong 2000). On the side of Korean consumers, "the chaebol is an important cultural entity [...] as groups of powerful and intelligent people". "This viewpoint can influence how consumers conceptualize chaebols' corporate personalities or images" (Sung, Tinkham 2005: 336). Chaebols differentiate themselves from non-chaebols not only in corporate governance, but also in capital structure, corporate investment, and brand equity (Kim et al. 2006; Almeida et al. 2015; e.g. Park et al. 2011).

Therefore, we need more detailed analyses, dividing our sample into chaebol and non-chaebol subsamples. For chaebols and non-chaebols respectively, we run quantile regressions for different levels of firm value and examine where NCSI could possibly affect firm value significantly.

\section{Data and model specification}

\subsection{Sample}

Our study targets firms listed on Korea Stock Exchange from the year 2000 to 2013. National Customer Satisfaction Index (NCSI) ${ }^{2}$ website, a working division of Korean Productivity Center (KPC).

NCSI parallels ACSI (American Customer Satisfaction Index) in the sense that NCSI's construction model comprises customers' expectation level, level of perceived quality,

\footnotetext{
${ }^{2}$ NCSI is an index of customer-satisfaction level of the products and services.
} 
level of perceived value, complaint level, and loyalty and retention rate for products and services. In other words, NCSI as well as ACSI are not seriously biased, because it includes all the temporal phases of customers' before-use, use, and after-use evaluations. It is an index designed to be "general enough to be comparable across firms, industries, sectors, and nations" (Fornell et al. 1996: 8). NCSI surveys are based on one-on-one, face-to-face interviews with customers who have experience with specific products and services. 278 customers per company are selected randomly. As NCSI usually deals with 230 representative organizations from 56 industries and sectors, the entire opinion poll includes almost $63,000(278 \times 230)$ sample customers. Each survey question has 10 -point scale and the overall end score for a company is converted into an index ranging from the minimum 0 to the maximum 100 .

We pooled sample firms' financial and stock data from FnGuide ${ }^{3}$ database and chaebol data from the website Fair Trade Commission ${ }^{4}$, Republic of Korea. Every year, Fair Trade Commission uploads the list of companies affiliated with large business conglomerates. We categorize them as "chaebol" if they belong to the list of a given year, otherwise as "non-chaebol".

As we proceeded to make our dataset, we excluded unlisted firms including non-profit organizations and government branches. We also excluded firms belonging to finance and insurance industries (KSIC code: K) because they differ from most of manufacturing industry firms in terms of financial configuration and government regulation. Firm-year observations whose total assets or sales are smaller than 0 were eliminated, and firms having no NCSI scores were also eliminated. Financial variables were all winsorized at the $1^{\text {st }}$ and $99^{\text {th }}$ percentiles, so that tilting of statistics due to extreme outliers should be circumvented. Our final sample comprises 48 firms (32 chaebols, 16 non-chaebols), having 375 firm-years ${ }^{5}$. SAS software version 9.4 was used for statistical analysis.

\subsection{Model specification}

We establish the following regression model according to O'Sullivan and McCallig (2012: 830-831) to examine the effects of customer satisfaction on firm value. "This model allows us to incorporate Tobin's q, accounting earnings and customer satisfaction in a model that is based on fundamental finance concepts".

\footnotetext{
${ }^{3}$ FnGuide provides financial information services in South Korea.

${ }^{4}$ FTC (Fair Trade Commission) is South Korea's regulatory authority for economic competition.

${ }^{5}$ The number of firms in our sample increases steadily from 20 (23.8\%) to 45 (21.0\% of total mkt. cap) from the year 2000 to 2013. As our sample contains 48 firms in total, this indicates that our NCSI firms existed quite stably throughout these years. From our sample, 20 firms belong to manufacturing industry (KSIC code C); 1 to utility (D); 5 to construction (F); 8 to trade (G); 5 to transportation $(\mathrm{H}) ; 8$ to communications $(\mathrm{J}) ; 1$ to high-tech service $(\mathrm{M})$. In a study on customer satisfaction, the inclusion of service industry firms is considered crucial. Whereas US industry classification has a highest category for service (SIC code 70-89), Korean classification does not. However, our sample still contains subcategories related to service, such as airlines (KSIC code 51), telecommunications (61), information service (63), as well as a highest category high-tech service (M). Therefore, we can conclude that our sample data are relatively evenly distributed throughout industries. NCSI scores, ranging from 56 to 58 , show the tendency to increase steadily year by year.
} 


$$
Q_{i, t}=\alpha_{0}+\alpha_{1} N C S I_{i, t}+\text { Controls }_{i, t}+\varepsilon_{i t}
$$

the dependent variable Tobin's $\mathrm{Q}\left(Q_{i, t}\right)$ in equation (1) represents firm value affected by firms' important decision-makings, managerial strategy-adoptions, etc. It is defined as the ratio of a firm's total market value to the firm's replacement costs. Tobin's Q usually has a high value, when a firm has positive-NPV investment opportunities through efficient asset managements; when a firm has already invested in R\&D with high future prospects; when a firm has lots of intangible assets such as brand, technology, etc.; when, in brief, its market value is higher than its sheer replacement costs. In our study, we calculate Tobin's Q as a firm's quasi-market value of assets divided by its total book assets. The numerator "quasi-market value of assets" is calculated as total assets minus the book value of common equity plus the market value of common equity.

The main explanatory variable $N_{C S I}$ is a score assigned to one firm for which we averaged multiple per-brand NCSI scores if the firm has more than one brand (or product) (à la Tuli, Bharadwaj 2009; Malshe, Agarwal 2015). The variable has the value range of $0-100$. Most of prior studies report that customer satisfaction (ACSI or NCSI) has statistically significant, or sometimes insignificant, effects on firm value. We expect that depending on selected quantiles of Tobin's Q customer satisfaction has different effects on firm value, i.e. Tobin's $Q$.

For control variables, the followings are known to affect firm value: R\&D investment ratio $\left(R \& D_{i, t}\right)$, advertising expenditure ratio $\left(A D_{i, t}\right)$, sales growth rate $\left(S G_{i, t}\right)$, book leverage $\left(L E V_{i, t}\right)$, and firm size $\left(S I Z E_{i, t}\right) . R \& D$ is calculated as $R \& D$ expenditures divided by total assets; $A D$ as advertising expenditures divided by total assets. Following Hirschey (1982) and Bublitz and Ettredge (1989), we expect that both $R \& D$ and $A D$ will have positive effects on firm value, i.e. on Tobin's Q. Moreover, $S G$ is calculated as sales at a given year minus sales a year before, all divided by the latter sales. As $S G$ reflects a firm's growth rate, we expect that $S G$ has positive effect on Tobin's Q. We expect that $L E V$, calculated as total debts divided by total assets, affects firm value either positively or negatively for the following reasons. Either the use of debt decreases the cost of capital due to tax shield effect, leading to $L E V$ 's positive effect on firm value; or the use of (too) much debt increases the cost of capital such as interest expense, bankruptcy cost, etc. resulting in $L E V$ having negative effect on firm value. SIZE is calculated as the natural logarithm of total assets, and we expect that SIZE has positive effect on firm value.

\section{Empirical Results}

\subsection{Summary statistics}

Table 1 reports the descriptive statistics of the variables. Panel A reports the whole sample, Panel B the subsample of chaebol firms, and Panel C the subsample of nonchaebol firms.

For the dependent variable Tobin's Q, the distribution is right-skewed, the mean larger than the median. The whole sample columns show that the mean of Tobin's Q is 1.518 , 
larger than the median 1.130. Here untabulated ${ }^{6}$, our normality test on Tobin's Q reports that its Jacque-Bera statistic $(=130,819.00, \mathrm{p}$-value $=0.000)$ rejects the null hypothesis of Tobin's Q normally distributed. This supports our use of quantile regressions (QR) modeling conditional quantiles rather than the mean.

At first look, the mean and the median deviate little from each other for NCSI, LEV, and SIZE, whether they are drawn from the whole, chaebol, or non-chaebol sample. The mean and the median deviate much for $R \& D, A D$, and $S G$. What is important for us is to check whether the variables have the significance of differences between chaebol and non-chaebol samples. We apply Wilcoxon rank sum tests to see two samples' (chaebol, non-chaebol) mean differences ${ }^{7}$. The last two columns in Table 1 report that chaebol and non-chaebol firms are significantly different in every aspect except $S G$. Between two subsamples, $R \& D, A D$, and SIZE are different at $1 \%$, Tobin's $Q, N C S I$, and $L E V$ at $5 \%$ significance level. Therefore, our motivation to test our model on the basis of two such separate samples is justified.

\subsection{The effects of customer satisfaction on firm value: whole sample analysis}

In this section, we examine the effects of customer satisfaction on firm value using Equation (1). For control variables from Equation (1), we include $R \& D, A D, S G, L E V$, and SIZE that are generally known to have impact on firm value.

Table 2 reports the regression results. The OLS estimation reveals that NCSI does not have statistically significant effect on firm value. Hereby it is recognized that for firms listed on Korea Stock Exchange customer satisfaction does not establish substantial contribution to firm value. One possible explanation for this counterintuitive result would be that firms having NCSI scores are well-established, highly-reputed firms in Korean markets and customers expect ever higher product quality from these firms. Therefore, a firm's expenditures to meet the claims from customer satisfaction would offset or lessen its value-increasing merits from customer satisfaction. At this point, it is required that we examine how NCSI's effects on firm value would turn out depending on chaebol and non-chaebol subsamples respectively.

Among control variables, both $R \& D$ and $A D$ have positive effects on firm value at the $1 \%$ significance level. This indicates that R\&D investments and advertising expenditures are substantial contributors to the enhancement of firm value. On the other hand, $L E V$ has positive effect on firm value at the $1 \%$ significance level. This implies that positive outcomes from issuing debt, i.e. tax shield effect, dominate its negative outcomes such as interest expense, bankruptcy cost, etc. SIZE has positive effect again at the $1 \%$ significance level. That is, larger firms have higher firm value.

Furthermore, Table 2 reports quantile regression results for the different quantiles of firm value. From 0.2 to 0.6 Tobin's Q quantile, NCSI does not relate to firm value significantly. This is in line with the results of our previous OLS regression. In 0.8

\footnotetext{
${ }^{6}$ The authors are ready to deliver all the untabulated tables from our article on request via our emails.

${ }^{7}$ Preliminary Shapiro-Wilk tests showed p-values smaller than 0.05 for all our variables and rejected null hypotheses that they are normally distributed.
} 


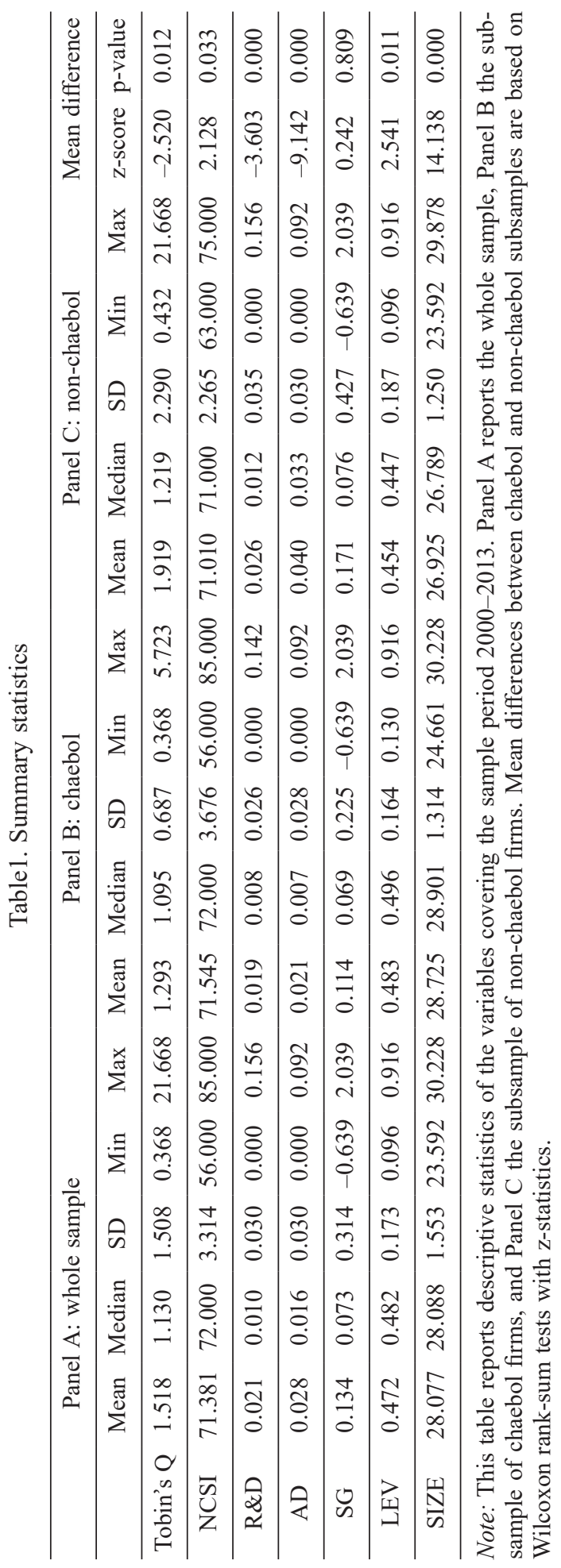


Tobin's Q quantile, however, NCSI has negative effect at the $10 \%$ significance level (coefficient $=-0.031$, standard error $=0.018$ ). Untabulated in Table 2, in 0.9 Tobin's $\mathrm{Q}$ quantile $N C S I$ has negative effect at the $1 \%$ level (coefficient $=-0.069$, standard error $=0.025$ ). An econometrically straightforward interpretation for this would be that, conditioning on all the control variables, a firm is likely to have high value if it has low, rather than high, customer satisfaction. For our more elaborate wording, we rephrase it as: customer satisfaction affects firm value negatively, especially when the firm is from the higher rank of value ${ }^{8}$. As it is repeatedly pointed out above, for highly valued firms whose market values are much higher than replacement costs, expenditures for investments in customer satisfaction might well exceed the benefits from such investments.

Table 2. The effects of customer satisfaction on firm value

\begin{tabular}{cccccc}
\hline \multirow{2}{*}{ OLS } & \multicolumn{4}{c}{ Selected Tobin's Q quantiles } \\
\cline { 3 - 6 } & & 0.2 & 0.4 & 0.6 & 0.8 \\
\hline \multirow{2}{*}{ NCSI } & -0.022 & 0.005 & -0.004 & -0.007 & $-0.031^{*}$ \\
& $(0.026)$ & $(0.004)$ & $(0.009)$ & $(0.011)$ & $(0.018)$ \\
\hline \multirow{2}{*}{ R\&D } & $27.433 * * *$ & $4.361^{* * *}$ & $7.742 * * *$ & $15.060 * * *$ & $38.375^{* * *}$ \\
& $(5.395)$ & $(1.023)$ & $(1.979)$ & $(3.955)$ & $(6.121)$ \\
\hline \multirow{2}{*}{ AD } & $12.144^{* *}$ & -0.502 & -0.558 & $-3.356^{*}$ & 1.140 \\
& $(6.138)$ & $(1.007)$ & $(1.565)$ & $(1.925)$ & $(4.555)$ \\
\hline \multirow{2}{*}{ SG } & 0.040 & -0.021 & 0.040 & 0.352 & 0.444 \\
& $(0.232)$ & $(0.099)$ & $(0.205)$ & $(0.306)$ & $(0.437)$ \\
\hline \multirow{2}{*}{ LEV } & $2.117 * * *$ & $0.422 * * *$ & -0.039 & 0.342 & -0.069 \\
& $(0.741)$ & $(0.115)$ & $(0.178)$ & $(0.242)$ & $(0.423)$ \\
\hline \multirow{2}{*}{ SIZE } & $0.970^{* * *}$ & -0.022 & $-0.053 *$ & $-0.186^{* * *}$ & -0.143 \\
& $(0.220)$ & $(0.021)$ & $(0.030)$ & $(0.051)$ & $(0.089)$ \\
\hline \multirow{2}{*}{ Intercept } & $-25.895 * * *$ & 0.855 & $2.766^{* * *}$ & $6.793 * * *$ & $7.491 * * *$ \\
& $(6.131)$ & $(0.701)$ & $(1.017)$ & $(1.619)$ & $(2.734)$ \\
\hline
\end{tabular}

Note: This table reports quantile regression results for selected Tobin's Q quantiles from 0.2 to 0.8 along with OLS regression results. The samples are firms listed on Korea Stock Exchange covering the periods 2000-2013. The dependent variable is Tobin's $\mathrm{Q}\left(Q_{i, t}\right)$. The explanatory variable is customer satisfaction $\left(N C S I_{i, t}\right)$. Control variables are $\mathrm{R} \& \mathrm{D}$ investment ratio $\left(R \& D_{i, t}\right)$, advertising expenditure ratio $\left(A D_{i, t}\right)$, sales growth rate $\left(S G_{i, t}\right)$, book leverage $\left(L E V_{i, t}\right)$, and firm size $\left(S I Z E_{i, t}\right)$. Standard errors are shown in parentheses. The standard errors in quantile regressions are computed by the Markov chain marginal bootstrap (MCMB) resampling method from $\mathrm{He}$ and $\mathrm{Hu}$ (2002). Our OLS regressions control for firm and year effects. ${ }^{* *}, * *$ and $*$ indicate significance levels at the $1 \%, 5 \%$ and $10 \%$ respectively.

\footnotetext{
${ }^{8}$ We thank an anonymous reviewer who pointed out possible inappropriateness in this. We included what he suggests as a more rigorous interpretation, and gave a twist on it in order to line it up with interpretations from OLS regressions. Possible errors and criticisms are all our responsibility.
} 
Among control variables, $R \& D$ has positive effects on firm value for all Tobin's $\mathrm{Q}$ quantiles at the $1 \%$ significance level. What is remarkable is that, as firm value increases from the lowest to the highest Tobin's Q quantile, the coefficient on $R \& D$ also increases monotonically. To be more specific, the coefficient on $R \& D$ is 4.361 for 0.2 Tobin's Q quantile, and 38.375 for 0.8 Tobin's Q quantile. These statistics imply that, as firm value increases higher, $R \& D$ investments contribute correspondingly all the more to the increasing firm value. $A D$ does not affect firm value significantly for most of Tobin's Q quantiles. $S G$, reflecting firms' growth potential, does not affect firm value in any significant way. $L E V$ positively affects firm value at the $1 \%$ significance level only for 0.2 Tobin's Q quantile. This corroborates that for undervalued firms debt's benefits are larger than its costs. Finally, SIZE affects firm value negatively only for 0.4 and 0.6 Tobin's Q quantiles, i.e. for medium-value firms.

\subsection{The effects of customer satisfaction on firm value: subsample analysis}

Chaebols are conglomerates in Korea, mostly owned by a family or a powerful large shareholder. Firms belonging to a chaebol group are likely to be altogether influenced by decisions from the top owner family (or shareholder), are easy of access to their internal capital markets, and are less likely to be afflicted by financial constraints (Shin, Park 1999; Chang, Hong 2000). Chaebol and non-chaebol firms differ in corporate governance, capital structure, brand equity, etc. Therefore, we investigate whether customer satisfaction affects firm value differently for chaebol and non-chaebol firms.

Table 3 reports statistical results. OLS regression estimates corroborate that for neither chaebol nor non-chaebol subsample NCSI has significant effects on firm value. Interestingly enough, for the chaebol subsample, the coefficient on $R \& D$ is not significant, but the coefficient on $A D$ turns out significant at the $1 \%$ level. We interpret this as indicative of the managerial strategy for already well-established chaebol brands that expenditures in advertising are more effective than investments in $R \& D$ for enhancing their firm value. For the non-chaebol subsample, reversely, the coefficient on $R \& D$ is significant at the $1 \%$ level, but the coefficient on $A D$ is rather insignificant. We realize that for non-chaebol firms, unlike chaebol firms, investments in $R \& D$ are crucial for their firm value. To reiterate the OLS estimation results, for chaebol firms $A D$ and $S G$ have significant and positive effects, whereas $L E V$ has significant and negative effect, on firm value. For non-chaebol firms, $R \& D, L E V$, and SIZE have significant and positive effects on firm value.

Quantile regression estimates suggest that NCSI does not have significant relation to firm value from any of Tobin's Q quantiles, either for chaebol or non-chaebol subsample. For chaebol subsample, $R \& D$ has significant and positive effect on firm value for 0.4 and 0.6 Tobin's Q quantiles, i.e. for firms of medium-level value; for 0.2 and 0.8 Tobin's $\mathrm{Q}$ quantiles, i.e. for firms of either low- or high-level value, $R \& D$ does not have any significant effect on firm value. However, for non-chaebol subsample, $R \& D$ exerts significant effects on firm value for all Tobin's $\mathrm{Q}$ quantiles. $R \& D$ 's regression coefficients from non-chaebol subsample are larger than those from chaebol subsample for all Tobin's Q quantiles; therefore, the positive impact of R\&D investments on firm value might well be regarded greater for non-chaebol firms than for chaebol firms. 
Table 3. The effects of customer satisfaction on firm value: chaebol vs non-chaebol

\begin{tabular}{cccccc}
\hline \multirow{5}{*}{ OLS } & \multicolumn{5}{c}{ Panel A: chaebol } \\
\cline { 3 - 6 } & & 0.2 & 0.4 & 0.6 & 0.8 \\
\hline \multirow{2}{*}{ NCSI } & 0.007 & 0.005 & 0.000 & 0.000 & 0.000 \\
& $(0.014)$ & $(0.004)$ & $(0.007)$ & $(0.010)$ & $(0.015)$ \\
\hline \multirow{2}{*}{ R\&D } & -4.752 & 1.545 & $2.963^{*}$ & $3.651^{* *}$ & 1.421 \\
& $(4.838)$ & $(0.953)$ & $(1.795)$ & $(1.843)$ & $(1.928)$ \\
\hline \multirow{2}{*}{ AD } & $8.947^{* *}$ & $5.817^{* * *}$ & $7.427^{* *}$ & $10.360^{* * *}$ & $22.755^{* * *}$ \\
& $(4.086)$ & $(1.630)$ & $(2.950)$ & $(3.947)$ & $(3.403)$ \\
\hline \multirow{2}{*}{ SG } & $0.409 * * *$ & 0.061 & 0.009 & -0.171 & $0.788^{*}$ \\
& $(0.143)$ & $(0.120)$ & $(0.189)$ & $(0.333)$ & $(0.442)$ \\
\hline \multirow{2}{*}{ LEV } & $-1.034^{* *}$ & $0.310^{* *}$ & -0.110 & -0.311 & $-0.407^{*}$ \\
& $(0.505)$ & $(0.152)$ & $(0.203)$ & $(0.220)$ & $(0.233)$ \\
\hline \multirow{2}{*}{ SIZE } & 0.213 & -0.032 & -0.023 & -0.096 & $-0.146^{* * *}$ \\
& $(0.145)$ & $(0.037)$ & $(0.056)$ & $(0.065)$ & $(0.054)$ \\
\hline \multirow{2}{*}{ Intercept } & -4.878 & 1.188 & 1.623 & $4.099^{* *}$ & $5.663^{* * *}$ \\
& $(3.919)$ & $(1.078)$ & $(1.592)$ & $(1.838)$ & $(2.002)$ \\
\hline \hline
\end{tabular}

Panel B: non-chaebol

\begin{tabular}{cccccc}
\hline \multirow{2}{*}{ OLS } & \multicolumn{4}{c}{ Selected Tobin's Q quantiles } \\
\cline { 3 - 6 } & & 0.2 & 0.4 & 0.6 & 0.8 \\
\hline \multirow{2}{*}{ NCSI } & -0.075 & -0.009 & -0.018 & -0.013 & -0.004 \\
& $(0.114)$ & $(0.032)$ & $(0.030)$ & $(0.031)$ & $(0.027)$ \\
\hline \multirow{2}{*}{ R\&D } & $49.738^{* * *}$ & $17.432 * *$ & $32.146 * * *$ & $46.821 * * *$ & $61.932 * * *$ \\
& $(13.864)$ & $(7.881)$ & $(3.926)$ & $(6.854)$ & $(6.525)$ \\
\hline \multirow{2}{*}{$\mathrm{AD}$} & 7.748 & -1.877 & -1.748 & -3.826 & -4.302 \\
& $(15.782)$ & $(3.237)$ & $(2.318)$ & $(2.789)$ & $(3.245)$ \\
\hline \multirow{2}{*}{$\mathrm{SG}$} & 0.705 & -0.319 & -0.124 & 0.616 & 0.518 \\
& $(0.685)$ & $(0.350)$ & $(0.550)$ & $(0.499)$ & $(0.518)$ \\
\hline \multirow{2}{*}{ LEV } & $4.119 * *$ & 0.307 & $0.573 *$ & 0.528 & 0.735 \\
& $(2.006)$ & $(0.505)$ & $(0.322)$ & $(0.412)$ & $(0.526)$ \\
\hline \multirow{2}{*}{ SIZE } & $2.343 * * *$ & 0.077 & $0.107 *$ & 0.104 & $0.191 * * *$ \\
& $(0.622)$ & $(0.075)$ & $(0.062)$ & $(0.070)$ & $(0.070)$ \\
\hline \multirow{2}{*}{ Intercept } & $-63.632 * * *$ & -0.809 & -1.070 & -1.147 & -4.077 \\
& $(18.535)$ & $(2.645)$ & $(2.643)$ & $(2.614)$ & $(2.599)$ \\
\hline
\end{tabular}

Note: This table reports quantile regression results for selected Tobin's Q quantiles from 0.2 to 0.8 along with OLS regression results. The samples are firms listed on Korea Stock Exchange covering the periods 2000-2013. The dependent variable is Tobin's Q $\left(Q_{i, t}\right)$. The explanatory variable is customer satisfaction $\left(N C S I_{i, t}\right)$. Control variables are $\mathrm{R} \& \mathrm{D}$ investment ratio $\left(R \& D_{i, t}\right)$, advertising expenditure ratio $\left(A D_{i, t}\right)$, sales growth rate $\left(S G_{i, t}\right)$, book leverage $\left(L E V_{i, t}\right)$, and firm size $\left(S I Z E_{i, t}\right)$. Panel A targets the chaebol subsample, Panel B the non-chaebol subsample. Standard errors are shown in parentheses. The standard errors in quantile regressions are computed by the Markov chain marginal bootstrap (MCMB) resampling method from $\mathrm{He}$ and $\mathrm{Hu}$ (2002). The OLS regressions control for firm and year effects. $* * *, * *$ and $*$ indicate significance levels at the $1 \%, 5 \%$ and $10 \%$ respectively. 
Moreover, for non-chaebol subsample, $R \& D$ 's coefficients are monotonically increasing as firm value increases (from bottom to top Tobin's Q quantile). This is indicative of the fact that $R \& D$ 's positive impact on firm value is a lot larger for firms of higher value than for those of lower value in the non-chaebol subsample. In the case of chaebol subsample, $A D$ has statistically significant effects on firm value for all Tobin's $\mathrm{Q}$ quantiles and $A D$ 's regression coefficients are monotonically increasing as firm value increases. This indicates that the positive impact of advertising expenditures on firm value is much larger for firms of higher value than for those of lower value in the chaebol subsample. In the non-chaebol subsample, to the contrary, $A D$ does not have significant effects on firm value for any of Tobin's Q quantiles.

Back to the chaebol subsample, SIZE affects firm value negatively for firms of high value as in 0.8 Tobin's Q quantile, whereas SIZE is not significant at all for firms of medium and low value as in less than 0.8 Tobin's Q quantiles. In the case of non-chaebol subsample, SIZE affects firm value positively for 0.8 Tobin's Q quantile, whereas SIZE is not significant for Tobin's Q quantiles below 0.8. As firm value hits the peak, firm size is a burden for chaebol firms, whereas it is a boost for non-chaebol firms (see Maksimovic, Phillips 2002) ${ }^{9}$.

To write a brief summary on Table 3, customer satisfaction (NCSI) does not have significant impact on firm value for any of Tobin's Q quantiles whatsoever from either chaebol or non-chaebol subsample. The effects of R\&D investments on the enhancing of firm value are greater for non-chaebol firms than for chaebol firms, and much greater for non-chaebol firms of higher value. The effects of advertising expenditures on the enhancing of firm value are significant for chaebol firms, not for non-chaebol firms, and much more significant for chaebol firms of higher value. Firm size (SIZE) affects firm value negatively for chaebol firms of higher value, whereas it affects it positively for non-chaebol firms of higher value. Otherwise, firm size is not significant by any means.

\subsection{Robustness checks using lagged variables}

We further take into account the time-lagging impacts of the independent variables in order to control for potential endogeneity in our contemporaneous OLS and quantile regressions. We enter our independent variables one- and two-year lagged and perform robustness checks for the entire sample, chaebol and non-chaebol subsample. Here untabulated, lagged regressions deliver qualitatively the same results as contemporaneous regressions previously did.

\section{Discussions}

This study investigates how a firm's non-financial indicator, i.e. customer satisfaction from the product markets, relates to the firm's value. Unlike prior literature reporting American customer satisfaction's (ACSI) substantial contribution to firm value in the US, this study only discovers that Korean customer satisfaction (NCSI) is irrelevant to

\footnotetext{
${ }^{9}$ Maksimovic and Phillips (2002) report from the US context that conglomerate firms are less productive than single-segment firms of similar size.
} 
firm value in the Korean context. Applying quantile regression analysis, we discover that customer satisfaction affects firm value significantly and negatively, in other words, gnaws on firm value especially when the firm is from the higher rank of value. As to why customer satisfaction does not contribute to firm value in the Korean market context, we enumerate the following four possible reasons: (1) The measuring of NCSI, a logical replica of ACSI, is unjustifiable in the Korean consumer markets; (2) The standard of Korean customers' satisfaction is insurmountably high, and attempts to satisfy them do not help to increase their product loyalty and (re)purchase intentions; (3) Firms with NCSI scores are mostly established firms forming monopoly or oligopoly in Korean product market sectors, and consumers have a limited number of average similar product options in such markets; thus, market structure dominates customer satisfaction. Customer satisfaction is irrelevant to what substantially increase firm value, such as innovation, market share, diversification, etc. (4) The costs of customer satisfaction exceed what is affordable for firm value, especially when the firms are sustaining the higher rank of value. These four reasons are suggestions for future research in the areas of, stepwise, consumer psychology, consumer market research, industrial organization, and corporate finance and accounting. However, this paper does not develop supportive or critical studies on them.

Reason (1) problematizes the construct of NCSI itself. Lee and Lim (2005) point out difficulties in applying ACSI model directly to the Korean contexts and propose guidelines for developing a new customer satisfaction index. Based on consumer data from a less developed market Northern Cyprus, Karatepe (2011), for example, adumbrates customer satisfaction on different metrics and understands it as involving service environment, interaction quality, and empathy. Reason (2) concerns the psychological-behavioral characteristics of Korean consumers. In this case, we are encouraged to undertake many individual- and group-level empirical studies on them in the actual market field. Reason (3) concerns industry-level market competition and firms' conduct within it. As with leverage, dividend, R\&D, and advertising, with customer satisfaction there can be "herding behavior" among firms within an industry (e.g. MacKay, Phillips 2005; Lee 2002; Cohen, Klepper 1992; Balasubramanian, Kumar 1990). Firms belonging to an industry come to share similar levels of customer satisfaction. In a monopolistic industry, on the other hand, in which "herding" stops at a dead end, customer satisfaction does not stand out as an issue. In either case, customer satisfaction as the value driver for firms drops out. Finally, our empirical study in this paper relates to the reason (4). In the following Conclusions, we discuss this with theoretical, managerial implications on the international scale.

\section{Conclusions}

Would customer satisfaction contribute to firm value, if firm-level financial characteristics were all controlled for? The answer was, customer satisfaction is irrelevant, and detracts from firm value especially when they are firms from the higher rank of value. Reinartz and Kumar (2002) claim that making all the customers satisfied and thereby loyal does not always continue to bring profits and can possibly deteriorate the firm's performance and value. There are "true friends" worthy of customer satisfaction efforts, but also 
"butterflies", "strangers", and "barnacles" for whom it is inappropriate. Our study is a financial testimony to Reinartz and Kumar's marketing insight. We can further investigate which corporate expenditures related to customer satisfaction deteriorate firm value. In this line of thought and empirical evidence, we claim that the efforts in the marketing, financial sciences to establish Customer Satisfaction Index as one of the valid indices for firm value would lose support; in the managerial fields, especially in the emerging markets, efforts and attention on customer satisfaction as a channel to boost up firm value should be reconsidered.

There are several limitations, of course, that need to be noted.

First, present study only examined the relation between customer satisfaction and firm value limited to Korean market. Therefore, to generalize the result of this study, future research should target and include more emerging countries in the sample.

Second, as contradicting academic research suggest, although the relationship between customer satisfaction and firm value has been embroiled in controversy, one recent research reported that employee satisfaction could bring marginally positive effect to firm value. We encourage researchers to further examine various antecedents of customer satisfaction which eventually will help managers to efficiently allocate firm's limited resources.

\section{References}

Ahn, T.; Kim, W. J. 2000. Impact of customer satisfaction on financial performance, Accounting Science Research 25(1): 75-121 (in Korean).

Almeida, H.; Kim, C. S.; Kim, H. B. 2015. Internal capital markets in business groups: evidence from the Asian financial crisis, Journal of Finance 70(6): 2539-2586.

https://doi.org/10.1111/jofi.12309

Anderson, E. W.; Fornell, C.; Lehmann, D. R. 1994. Customer satisfaction, market share, and profitability: findings from Sweden, Journal of Marketing 58(3): 53-66.

https://doi.org/10.2307/1252310

Anderson, E. W.; Fornell, C.; Mazvancheryl, S. K. 2004. Customer satisfaction and shareholder value, Journal of Marketing 68(4): 172-185.

https://doi.org/10.1509/jmkg.68.4.172.42723

Balasubramanian, S. K.; Kumar, V. 1990. Analyzing variations in advertising and promotional expenditures: key correlates in consumer, industrial, and service markets, Journal of Marketing 54(2): 57-68. https://doi.org/10.2307/1251870

Blitz, D.; Pang, J.; van Vliet, P. 2013. The volatility effect in emerging markets, Emerging Markets Review 16: 31-45. https://doi.org/10.1016/j.ememar.2013.02.004

Bublitz, B.; Ettredge, M. 1989. The information in discretionary outlays: advertising, research, and development, Accounting Review 64(1): 108-124.

Chang, S. J.; Hong, J. 2000. Economic performance of group-affiliated companies in Korea: intragroup resource sharing and internal business transactions, Academy of Management Journal 43(3): 429-448. https://doi.org/10.2307/1556403

Claessens, S.; Yurtoglu, B. B. 2013. Corporate governance in emerging markets: a survey, Emerging Markets Review 15: 1-33. https://doi.org/10.1016/j.ememar.2012.03.002

Cochran, P. L.; Wood, R. A. 1984. Corporate social responsibility and financial performance, Academy of Management Journal 27(1): 42-56. https://doi.org/10.2307/255956

Cohen, W. M.; Klepper, S. 1992. The anatomy of industry R\&D intensity distributions, American Economic Review 82(4): 773-799. 
Cooper, R. G. 1984. How new product strategies impact on performance, Journal of Product Innovation Management 1(1): 5-18. https://doi.org/10.1111/1540-5885.110005

FnGuide Database. 2014. [online], [cited 15 January 2015]. Available from internet: http://www. fnguide.com

Fornell, C.; Johnson, M. D.; Anderson, E. W.; Cha, J.; Bryant, B. E. 1996. The American customer satisfaction index: nature, purpose, and findings, Journal of Marketing 60(4): 7-18. https://doi.org/10.2307/1251898

Fornell, C.; Morgeson, F. V.; Hult, T. M. 2016. An abnormally abnormal intangible: stock returns on customer satisfaction, Journal of Marketing 80(5): 122-125.

https://doi.org/10.1509/jm.16.0248

Fornell, C.; Mithas, S.; Morgeson III, F. V.; Krishnan, M. S. 2006. Customer satisfaction and stock prices: high returns, low risk, Journal of Marketing 70(1): 3-14.

https://doi.org/10.1509/jmkg.2006.70.1.3

FTC (Fair Trade Commission) Database. 2015. [online], [cited 15 October 2015]. Available from internet: http://www.ftc.go.kr

Harvey, C. R. 1995. Predictable risk and returns in emerging markets, Review of Financial Studies 8(3): 773-816. https://doi.org/10.1093/rfs/8.3.773

He, X.; Hu, F. 2002. Markov chain marginal bootstrap, Journal of the American Statistical Association 97(459): 783-795. https://doi.org/10.1198/016214502388618591

Hirschey, M. 1982. Intangible capital aspects of advertising and R\&D expenditures, Journal of Industrial Economics 30(4): 375-390. https://doi.org/10.2307/2097924

Huselid, M. A. 1995. The impact of human resource management practices on turnover, productivity, and corporate financial performance, Academy of Management Journal 38(3): 635-672. https://doi.org/10.2307/256741

Ittner, C. D.; Larcker, D. F. 1998. Are nonfinancial measures leading indicators of financial performance? An analysis of customer satisfaction, Journal of Accounting Research 36: 1-35. https://doi.org/10.2307/2491304

Karatepe, O. M. 2011. Service quality, customer satisfaction and loyalty: the moderating role of gender, Journal of Business Economics and Management 12(2): 278-300.

https://doi.org/10.3846/16111699.2011.573308

Kim, H.; Heshmati, A.; Aoun, D. 2006. Dynamics of capital structure: the case of Korean listed manufacturing companies, Asian Economic Journal 20: 275-302.

https://doi.org/10.1111/j.1467-8381.2006.00236.x

Koenker, R.; Bassett, G. 1978. Regression quantiles, Econometrica 46(1): 33-50.

https://doi.org/10.2307/1913643

Lee, C.-Y. 2002. Industry R\&D intensity distributions: regularities and underlying determinants, Journal of Evolutionary Economics 12(3): 307-341.

https://doi.org/10.1007/s00191-002-0117-9

Lee, H.; Lim, J. 2005. Measuring customer satisfaction: evaluation of NCSI and KCSI and suggestions for developing a new index, Korea Marketing Review 20(3): 137-160 (in Korean).

Luo, X.; Homburg, C.; Wieseke, J. 2010. Customer satisfaction, analyst stock recommendations, and firm value, Journal of Marketing Research 47(6): 1041-1058.

https://doi.org/10.1509/jmkr.47.6.1041

MacKay, P.; Phillips, G. M. 2005. How does industry affect firm financial structure?, Review of Financial Studies 18(4): 1433-1466. https://doi.org/10.1093/rfs/hhi032

Maksimovic, V.; Phillips, G. 2002. Do conglomerate firms allocate resources inefficiently across industries? Theory and evidence, Journal of Finance 57(2): 721-767.

https://doi.org/10.1111/1540-6261.00440 
Malshe, A.; Agarwal, M. K. 2015. From finance to marketing: the impact of financial leverage on customer satisfaction, Journal of Marketing 79(5): 21-38. https://doi.org/10.1509/jm.13.0312

National Customer Satisfaction Index (NCSI) Database. 2016. [online], [cited 20 March 2016] Available from internet: http://www.NCSI.or.kr/NCSI/NCSI_new/company.asp

O’Sullivan, D.; McCallig, J. 2012. Customer satisfaction, earnings and firm value, European Journal of Marketing 46(6): 827-843. https://doi.org/10.1108/03090561211214627

Park, Y.-R.; Lee, J. Y.; Hong, S. 2011. Effects of international entry-order strategies on foreign subsidiary exit: the case of Korean chaebols, Management Decision 49(9): 1471-1488.

https://doi.org/10.1108/00251741111173943

Park, S. J.; Kim, H. C. 2003. Customer satisfaction index and business performance, Marketing Research 18(3): 19-50 (in Korean).

Pauwels, K.; Silva-Risso, J.; Srinivasan, S.; Hanssens, D. M. 2004. New products, sales promotions, and firm value: the case of the automobile industry, Journal of Marketing 68(4): 142-156. https://doi.org/10.1509/jmkg.68.4.142.42724

Reinartz, W.; Kumar, V. 2002. The mismanagement of customer loyalty, Harvard Business Review 80(7): 86-95.

Servaes, H.; Tamayo, A. 2013. The impact of corporate social responsibility on firm value: the role of customer awareness, Management Science 59(5): 1045-1061.

https://doi.org/10.1287/mnsc.1120.1630

Shin, H. H.; Park, Y. S. 1999. Financing constraints and internal capital markets: evidence from Korean "chaebols", Journal of Corporate Finance 5(2): 169-191.

https://doi.org/10.1016/S0929-1199(99)00002-4

Sorescu, A.; Sorescu, S. M. 2016. Customer satisfaction and long-term stock returns, Journal of Marketing 80(5): 110-115. https://doi.org/10.1509/jm.16.0214

Sung, Y.; Tinkham, S. F. 2005. Brand personality structures in the United States and Korea: common and culture-specific factors, Journal of Consumer Psychology 15(4): 334-350.

https://doi.org/10.1207/s15327663jcp1504_8

The Economist. 2001. Finance and economics: touchy-feely. May 17, 2001: 68.

The Economist. 2012. The magic of good service. September 22, 2012: 78.

Tuli, K. R.; Bharadwaj, S. G. 2009. Customer satisfaction and stock returns risk, Journal of Marketing 73(6): 184-197. https://doi.org/10.1509/jmkg.73.6.184

Vomberg, A.; Homburg, C.; Bornemann, T. 2015. Talented people and strong brands: the contribution of human capital and brand equity to firm value, Strategic Management Journal 36(13): 2122-2131. https://doi.org/10.1002/smj.2328

Hyunseok KIM is currently a FRM, PhD candidate in SKK Business School, Sungkyunkwan University (South Korea). His research interests include corporate finance, asset pricing, risk management and international finance.

Jaisang KIM is currently a $\mathrm{PhD}$ candidate in Shidler College of Business, University of Hawaii at Manoa (United States). His research interests include customer relationship management, social media, marketing - finance interface.

Kyeong-Seop CHOI is lecturer in philosophy and liberal arts at a number of universities in Seoul, South Korea. He received his BA in philosophy from University of California, San Diego, MA and $\mathrm{PhD}$ in philosophy from University of Würzburg, Germany. He published numerous articles on philosophy and cultural studies in Idealistic Studies (US) and Filozofia (Slovakia). He has also completed coursework for PhD in business in SKK Business School, Sungkyunkwan University (South Korea). His research interests are consumer culture, marketing philosophy, marketing-finance interface, and corporate finance. 